\title{
POPULAÇÃO E SINTOMAS DE Thaumastocoris peregrinus (HEMIPTERA: THAUMASTOCORIDAE) EM PLANTAS DE EUCALIPTO
}

\author{
Ivan da Costa Ilhéu Fontan ${ }^{1}$ \\ Marlon Michel Antônio Moreira Neto ${ }^{2}$ \\ Sharlles Christian Moreira Dias ${ }^{3}$
}

\begin{abstract}
Resumo: O objetivo do presente estudo foi monitorar a evolução dos sintomas do ataque e o aumento populacional de Thaumastocoris peregrinus em plantios de eucalipto avaliando seus instantes de máxima expressão e suas implicações no manejo integrado deste inseto. Foram utilizados clones híbridos de Eucalyptus urophylla (PL-3335, PL-3336 e PL-40) plantados na região centro-norte de Minas Gerais. Cada uma das três repetições do experimento foi composta por três árvores de onde foram coletados ramos da porção mediana da copa em sete ocasiões diferentes (0, 7, 21, 38, 54, 83 e 102 dias) Em cada avaliação foram contabilizados o número total de insetos (adultos e ninfas) e folhas nos ramos, e realizada uma avaliação visual da expressão dos sintomas nas plantas (escala de notas de severidade). Foi evidenciada a preferência do inseto pelos PL-3336 e PL-40, e a resistência natural das plantas do clone PL-3335. A expressão máxima dos sintomas nas plantas não ocorreu em sincronia temporal com o ápice populacional do inseto na área, sugerindo que o manejo de T. peregrinus seja baseado na identificação precoce e monitoramento populacional.
\end{abstract}

Palavras-chave: Eucalipto; Manejo integrado; Thaumastocoris peregrinus.

\footnotetext{
${ }^{1}$ Instituto Federal do Espírito Santo - Campus Ibatiba, Brasil. E-mail: ivanfontan.florestal@gmail.com.

2 Plantar - P\&D, Brasil. E-mail: marlon-moreira@hotmail.com.

3 Plantar - P\&D, Brasil. E-mail: sharlles.dias@gmail.com.
} 